\title{
European Society of Pediatric Research at Its 50th Anniversary: Past, Present, and Future
}

\author{
ROLF ZETTERSTRÖM \\ Acta Paediatrica, Karolinska University Hospital, Stockholm 171 76, Sweden
}

$\mathrm{F}$ ifty years ago, the European Society of Pediatric Research (ESPR) was initially formed as a club for European pediatric investigators. During the annual meeting in Interlaken, Switzerland, in 1969, a mere $10 \mathrm{y}$ after their first meeting, the Club adopted a constitution and became a professional Society now known as the ESPR.

Today's pediatric scientists live in a world quite different from their colleagues of $50 \mathrm{y}$ ago. At that time, those who survived World War II were still suffering psychological trauma from the war. Because of the European, postwar geopolitical climate, the first two international pediatric congresses were held in New York and Havana. By 1955, the situation in Europe had stabilized, and the Third Congress was held in Copenhagen.

Despite the war, economic collaboration between countries began rather soon following its end. The drive to work in partnership was particularly strong in Switzerland, a country that had taken in a great number of refugees from occupied countries because of its neutrality during the war.

In the medical field, the first real attempt to begin European scientific collaboration was made by Guido Fanconi, whose international standing made him particularly suited for this task (Fig. 1). With the aim of bringing together young promising pediatric investigators from various European countries, Fanconi arranged a meeting in Zürich, in October 1954, to discuss the disturbances of water and electrolyte metabolism during childhood. Fanconi invited pediatricians who had been recommended by national pediatric societies throughout Europe. Altogether 25 young pediatricians and a few internationally known senior pediatricians, including H. Hungerland from Giessen, W. Linneweh from Marburg, and W. Ströder from Wurzburg, were invited to participate in the conference. In addition, C. Lowe was invited to represent US pediatrics. Participants made presentations of their scientific work, which were published as articles in Helvetica Pediatrica ACTA (1955, volume 10). Conference participants stayed in the homes of Fanconi's friends and local pediatricians in

Received August 31, 2010; accepted September 1, 2010.

Correspondence: Rolf Zetterström, M.D., Ph.D., Acta Paediatrica, Karolinska University Hospital, Karolinska vägen 29, S-171 76 Stockholm, Sweden; e-mail: rolf.zetterstrom@actapaediatrica.se

Presented at the 2009 Annual Meeting of the European Society for Pediatric Research, Hamburg, Germany.

The photographs shown in this article are taken from a photo album given to the participants of the first meeting of the Club in 1959. The album was prepared by the staff at the Children's Hospital in Bonn on the initiative of Professor H. Hungerland.
Zurich. A general banquet was arranged in a restaurant, which, according to Fanconi, had opened before America had been discovered. The best result of the Zurich conference was that it started a productive and long-lasting dialogue between European pediatricians. In fact, at this conference, Lowe proposed the foundation of a joint European-US pediatric journal, which $9 \mathrm{y}$ later, resulted in the publication of the first issue of Pediatric Research.

\section{The Foundation of a Club and ESPR}

After the conference in Zurich, Fanconi continued his efforts to unite European pediatricians. In 1957, 2 y after the western part of Germany had joined NATO, Fanconi arranged an international symposium on renal disorders held in conjunction with the annual meeting of the German Pediatric Association, in Düsseldorf. The participants attending this symposium had all taken part in the conference in Zurich in 1954. After the symposium, the speakers met at a local winery to discuss the foundation of a European club for pediatric research. By unanimous decision, the group voted to found a Club similar to the US Society for Pediatric Research, whose regular membership would include young investigators. Although senior and established pediatric scientists could be invited to join the meetings of the Club, they could not become part of the voting membership. Although Fanconi was never invited to become a member of the Club, his initial effort, bringing European pediatric scientists together, contributed to its founding. Ettore Rossi, chairman of the Department of Pediatrics at the University in Bern, was appointed honorary secretary of the Club. He remained secretary of the Club through 1969, when the Club reformed as the ESPR. Rossi was an efficient honorary secretary, and the members of the Club were extremely grateful to him for his devoted work.

\section{The Annual Meetings of the Club and ESPR}

The first meeting of the Club was held in June 1959 in Bonn, which was then the seat of the West German government. Heinz Hungerland, Professor of Pediatrics at the University in Bonn, had been appointed as the President of the Club and organized this meeting. In addition to being one of the leading pediatric scientists in Germany, Hungerland was appreciated by his French colleagues because of his service and devotion to reorganize pediatric care in France after the country's liberation.

Almost all European pediatric scientists, who contributed to the rapid development of pediatric medical care in the middle of the 
1950s, attended the first meeting of the Club (Figs. 2 and 3). The main topics of this first meeting were neonatology, inborn errors of metabolism, renal diseases, and nutrition. Following the meeting, participants were taken for a sightseeing tour, which began with a visit to the Cloister Church Maria Laach (Fig. 4) and ended with a trip along the Mosel river with stops at local

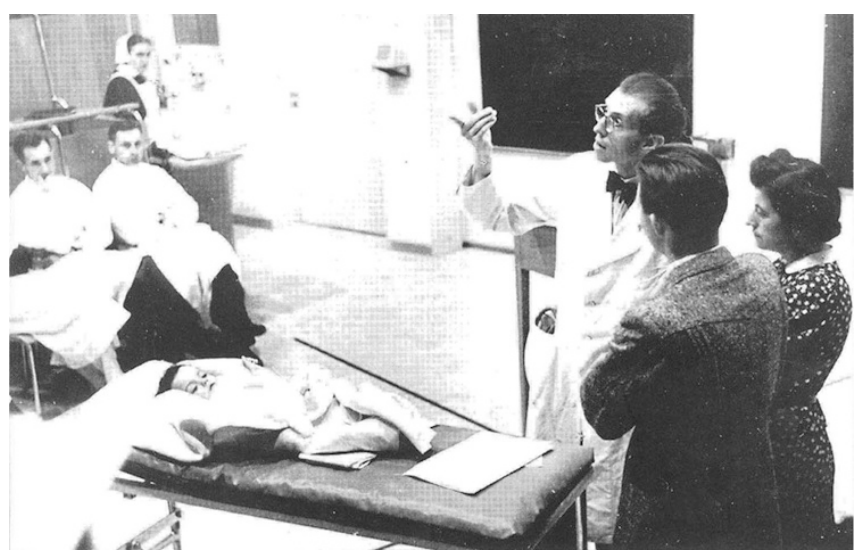

Figure 1. Professor Guido Fanconi is demonstrating technique on a patient when lecturing to graduate and undergraduate students. wineries. The meeting in Bonn was followed by annual meetings in Groningen, Holland (1960), Ferrara, Italy (1961), and Barcelona, Spain (1962).

The last meeting of the Club was held in Interlaken in 1969, where a discussion about the future direction of the Club took place. During the 1960s, several pediatric subspecialists had begun arranging conferences in their own fields and subspecialty societies were beginning to form. For example, at this last meeting of the Club in Interlaken, pediatricians specializing in hematology and immunology formed a group that met in conjunction with the first meeting of the ESPR, which was held the following year in Stockholm.

The difficulty of keeping pediatric researchers together in a single society grew during the years following the Stockholm meeting. Pediatric oncologists, originally considered pediatric hematologists, who treated children with leukemia, founded a society of pediatric oncology. Some immunologists were more in favor of belonging to a society for pediatric allergology than pediatric immunology. The same trend could be found in other subspecialties. However, the dream of having one single society for European pediatric research remained.

At the meeting held in Lyon, France, in September 1996, B. Salle, who was then President of the ESPR, brought together as
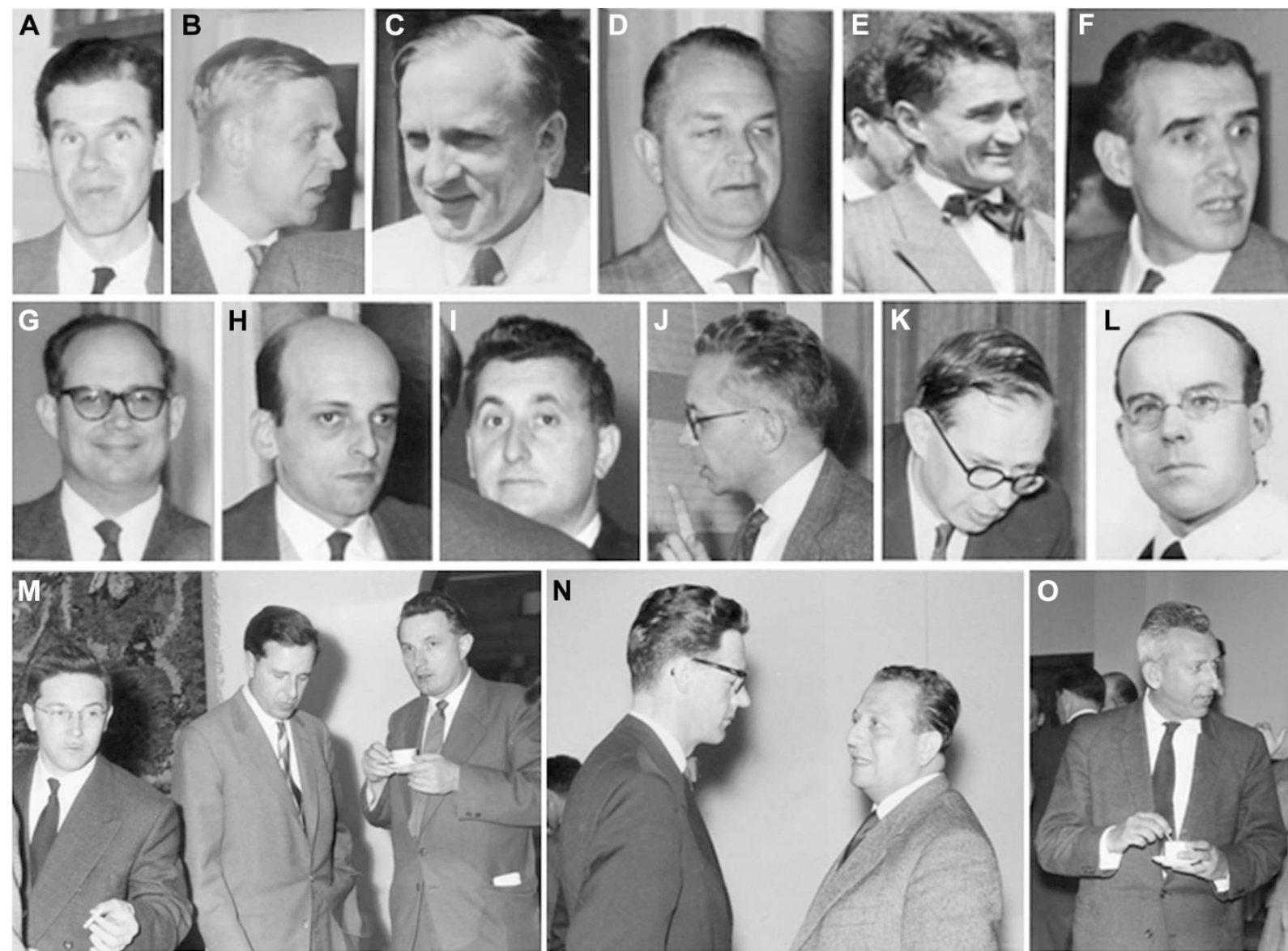

Figure 2. Eighteen of the founders of the Club at the meeting in 1959. (A) B. Friis-Hansen, Denmark; $(B) \mathrm{J}$. Vesterdahl, Denmark (President in Copenhagen 1967); (C) N. Hallman, Finland (President in Helsinki 1963); (D) W. Droese, Germany; $(E)$ R. François, France; $(F)$ P. Royer, France (President in Paris 1964); $(G)$ P. Durand, Italy; $(H)$ H. Menano, Portugal; $(I)$ A. Ballabriga, Spain (President in Barcelona 1962); $(J)$ A. Prader, Switzerland; $(K)$ T. Stapleton, United Kingdom; (L) P. Tizard, United Kingdom (President in Brighton 1971); (M) (left to right) L. Corbeel, Belgium; H. Bickel, Germany (President in Heidelberg 1972); and W. Swoboda, Austria (President in Vienna 1968); (N) R. Zetterström, Sweden (President in Stockholm 1970, left) and E. Rossi, Switzerland (Honorary Secretary 1959-1968 and President in Interlaken 1969, right); and (O) A. Minkowski, France. 

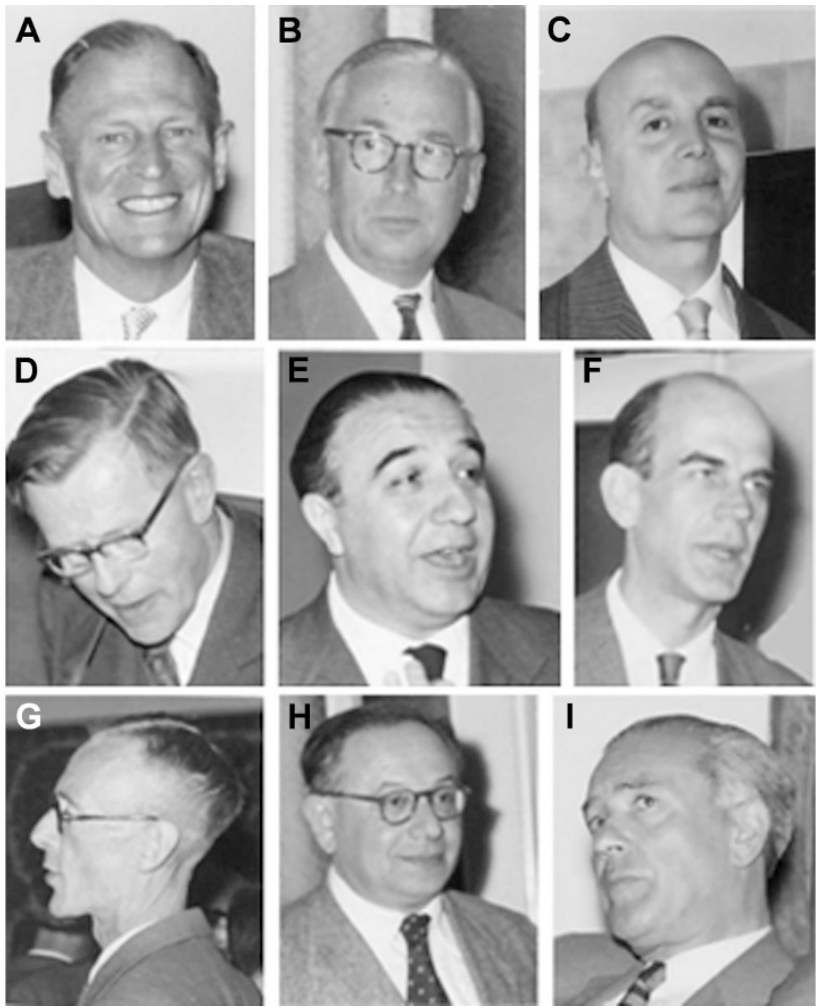

Figure 3. Leading European pediatric scientists, who were invited to participate in the first meeting of the Club. (A) H. Hungerland, Gemany (President in Bonn 1959); (B) W. Linneweh, Gemany; (C) E. Schwarz Tiene, Italy (President in Ferrara 1961); (D) P. Jonxis, The Netherlands, (President in Grooningen 1960); (E) M. Suarez, Spain (President in Sevilla 1973); $(F)$ J. Lind, Sweden; $(G)$ R.A. McCance, United Kingdom; $(H)$ A. Holzel, United Kingdom (President in Manchester 1965); and (I) Kerpel-Fronius, Hungary.

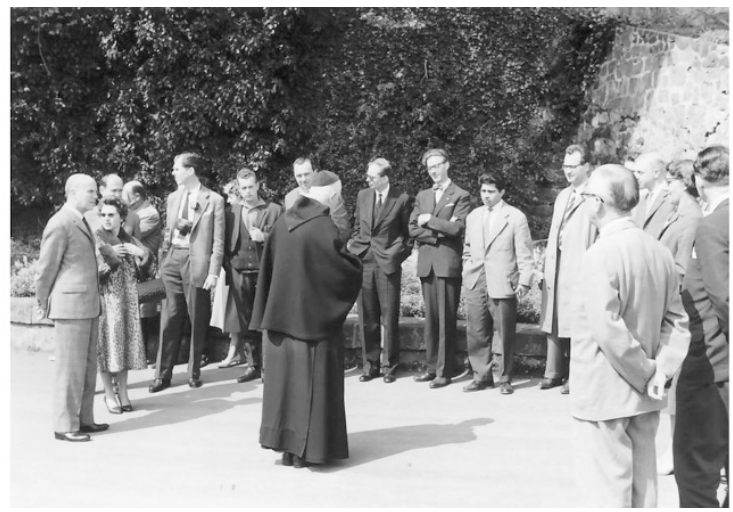

Figure 4. A sightseeing trip to the Romanesque cloister-church Maria Lach after the first scientific meeting of the Club for Pediatric Research. A monk recounts the history of the church to a group of participants.

many representatives of the various subgroups in pediatric research as possible. Through his diligent effort, as well as the efforts of many others, the ESPR has thrived. As a testament to the success and importance of the society, 2730 delegates from 95 different countries attended the 2008 Congress held in Nice, France.

\section{The 50th Anniversary Congress in Hamburg in 2009}

Approximately 1200 participants from 69 countries attended the 50th Annual Meeting of ESPR, which was held in Hamburg,
Germany, in October 2009. Many platform $(n=171)$ and poster $(n=542)$ presentations given at this meeting were interesting and clinically relevant (Abstracts of the 50th Annual Meeting of the European Society for Pediatric Research, 9-12 October 2009, Hamburg, Germany. Acta Paediatr 98(suppl):1-292). A great number of the abstracts presented at the meeting dealt with neonatological problems. Also of note, several of the poster presentations were made by pediatric scientists from countries previously not particularly productive in pediatric research. For instance, pediatricians from Saudi Arabia in the laboratory of S. $\mathrm{Al}$-Abdi presented posters on different fields of neonatology, e.g. the relation between G-6-PD deficiency and neonatal jaundice.

Participants of the Hamburg Congress received a booklet containing a short history of the ESPR and the Society's goals and views regarding its future. A timeline of the venues and organizers of previous meetings of the Club and the ESPR is given, but it was not clearly mentioned that the decision to found the Club was made in Bern in 1958 and that the first meeting, organized by H. Hungerland, was held in Bonn in 1959.

\section{Reflections About Future Scientific Priority Fields of ESPR}

When the Club was founded, reports from all main pediatric subspecialties, such as developmental physiology (pedology, according to Linneweh), inborn errors of metabolism, electrolyte homeostasis under normal and pathological conditions, and nutrition, were presented. Neonatology, which has been the predominant field represented at recent congresses, was the subject of a limited number of papers in the beginning.

Over the years, many new pediatric subspecialty societies have been founded. Some of them also support journals in their subspecialties. Although the rise of subspecialty groups has diminished the original aim of the ESPR, effort has been made to support subspecialty groups within ESPR, e.g. B. Salle's efforts at the congress in Lyon, 1996. The same sentiment was reiterated at the 50th Anniversary of the ESPR in 2009, when President N. Marlow proposed closer collaboration between representatives of the various subgroups and ESPR. He expressed a hope that the various sections of ESPR, such as those for circulation, epidemiology, and neonatology, would support such a plan.

At the meeting in October 2009, many members agreed that there are many compelling reasons to integrate the various fields of pediatric research into one main society. Undoubtedly, specialists in various fields will continue to meet to discuss their special problems, to plan joint research projects, and to organize training courses for young investigators. Entropy happens. However, studies with new techniques, such as the nanotechnique of cell organelles and individual molecules, will increase our understanding about the way in which structure and function of various tissues and organs are integrated under normal and pathological conditions. Although advancement of pediatric research in each subspecialty is necessary, collaboration between the pediatric scientists of different subspecialties benefits all. Therefore, going forward, perhaps a more gestalt approach, as offered by the ESPR, which aims to bring together experts in various disciplines, will be needed for further advancements in pediatric research. 